\section{BMJ Open Respiratory Research}

\title{
Pneumomediastinum in marijuana users: a retrospective review of 14 cases
}

\author{
Zoe Freeman Weiss, ${ }^{\oplus 1}$ Sara Gore, ${ }^{2}$ Andrew Foderaro ${ }^{3}$
}

\begin{abstract}
To cite: Weiss ZF, Gore S, Foderaro A. Pneumomediastinum in marijuana users: a retrospective review of 14 cases. BMJ Open Resp Res 2019;6:e000391. doi:10.1136/ bmjresp-2018-000391
\end{abstract}

- Additional material is published online only. To view please visit the journal online (http://dx.doi.org/10.1136/ bmjresp-2018-000391)

Received 10 December 2018 Revised 7 January 2019 Accepted 8 January 2019

\section{Check for updates}

(C) Author(s) (or their employer(s)) 2019. Re-use permitted under CC BY-NC. No commercial re-use. See rights and permissions. Published by BMJ.

${ }^{1}$ Department of Internal Medicine, Warren Alpert Medical School of Brown University, Providence, Rhode Island, USA

${ }^{2}$ Division of Infectious Diseases, Oregon Health and Science University, Portland, Oregon, USA

${ }^{3}$ Division of Pulmonary and Critical Care and Department of Internal Medicine, Warren Alpert Medical School of Brown University, Providence, Rhode Island, USA

Correspondence to Dr Zoe Freeman Weiss: zoefreemanweiss@gmail.com

\section{ABSTRACT}

Introduction Inhaled marijuana has been infrequently identified as a potential risk factor for the development of spontaneous pneumomediastinum (SPM), a rare finding of free air in the mediastinum likely caused by barotrauma during breathing manoeuvres. The mechanism of inhalation drug use is often not ascertained by physicians, thus little is known about how different smoking techniques precipitate pulmonary injury. We aimed to evaluate the frequency of marijuana use in patients with non-traumatic pneumomediastinum over a 12-month period, identifying additional relevant clinical features or risk factors, and determining the extent to which clinicians record smoking techniques.

Methods We performed a retrospective chart review over a 1-year period, identifying patients presenting to the hospital with a diagnosis of pneumomediastinum in the absence of trauma, malignancy or iatrogenic cause. Results We identified 21 cases, 14 of which (66.7\%) were associated with marijuana use, average age was 22.5 years (range 18-30), with male predominance $(64.2 \%)$. Daily or more use was reported in $50 \%$ of cases. Concurrent risk factors including vomiting (57.1\%) and coughing (42.9\%) were commonly present. The mechanism of smoking was described in only two cases (14.3\%).

Discussion Inhaled marijuana may be an underappreciated risk factor for the development of SPM, caused by air leakage around the bronchovascular sheaths during successive inhalation through a high-resistance smoking apparatus or forced exhalation against a closed glottis. Physicians should be aware of this association in order to provide appropriate counselling. Further research is needed to direct the safe use of smoking devices and techniques.

\section{INTRODUCTION}

Pneumomediastinum (PM) is diagnosed by the radiographic finding of free air in the mediastinum, and is often called spontaneous pneumomediastinum (SPM) in the absence of trauma or a clear secondary cause. The incidence of this condition is reported between $0.001 \%$ and $0.014 \%$ of hospitalised patients and is more common among young adult males. ${ }^{1}$ Symptoms include chest pain (which can be severe), dyspnoea, neck pain and dysphagia. Subcutaneous crepitus and auscultated 'crunching' heard over the chest (Hamman's sign) may

\section{Key message}

Inhaled marijuana may be an underappreciated risk factor for the development of spontaneous pneumomediastnum.

be appreciated on examination. Radiologic imaging of the chest, including X-ray or CT, is the gold standard for diagnosis and shows extraluminal gas within the mediastinum $^{2}$ (figure 1). SPM is typically benign, resolving over a few weeks, though can occasionally be complicated by pneumothorax, cardiac tamponade or tracheal compression. ${ }^{2}$ Extensive workup to rule out hollow organ rupture (eg, swallow studies or endoscopy) is not warranted except in cases of suspected trauma to the oesophagus. ${ }^{3}$ SPM can be induced by asthma attacks, forceful straining, childbirth, weight lifting, diabetic ketoacidosis, coughing or vomiting. Many of the above causes are thought to result from alveolar rupture in the setting of increased intrathoracic pressure. Though these are technically secondary causes, the non-traumatic aetiologies are often characterised as spontaneous. ${ }^{4}$

Marijuana is an increasingly common substance that is used both for recreational and medicinal purposes. Inhalational use of marijuana has been associated with respiratory symptoms such as chronic cough, sputum production, dyspnoea and hoarseness, ${ }^{5}$ and has recently been described as a possible risk factor for chronic bullous lung disease and secondary pneumothorax, though causality has not been robustly studied. ${ }^{6-8}$ Fewer than 10 published case reports document the use of marijuana in cases of SPM, ${ }^{9-17}$ of which only one describes the size and dimensions of the smoking apparatus and the technique used. ${ }^{15}$ Twenty published case series and retrospective cohort studies have documented over a thousand total cases of PM, ${ }^{18}$ yet only four studies cite marijuana use as a specific predisposing or precipitating factor ${ }^{19-22}$ in 


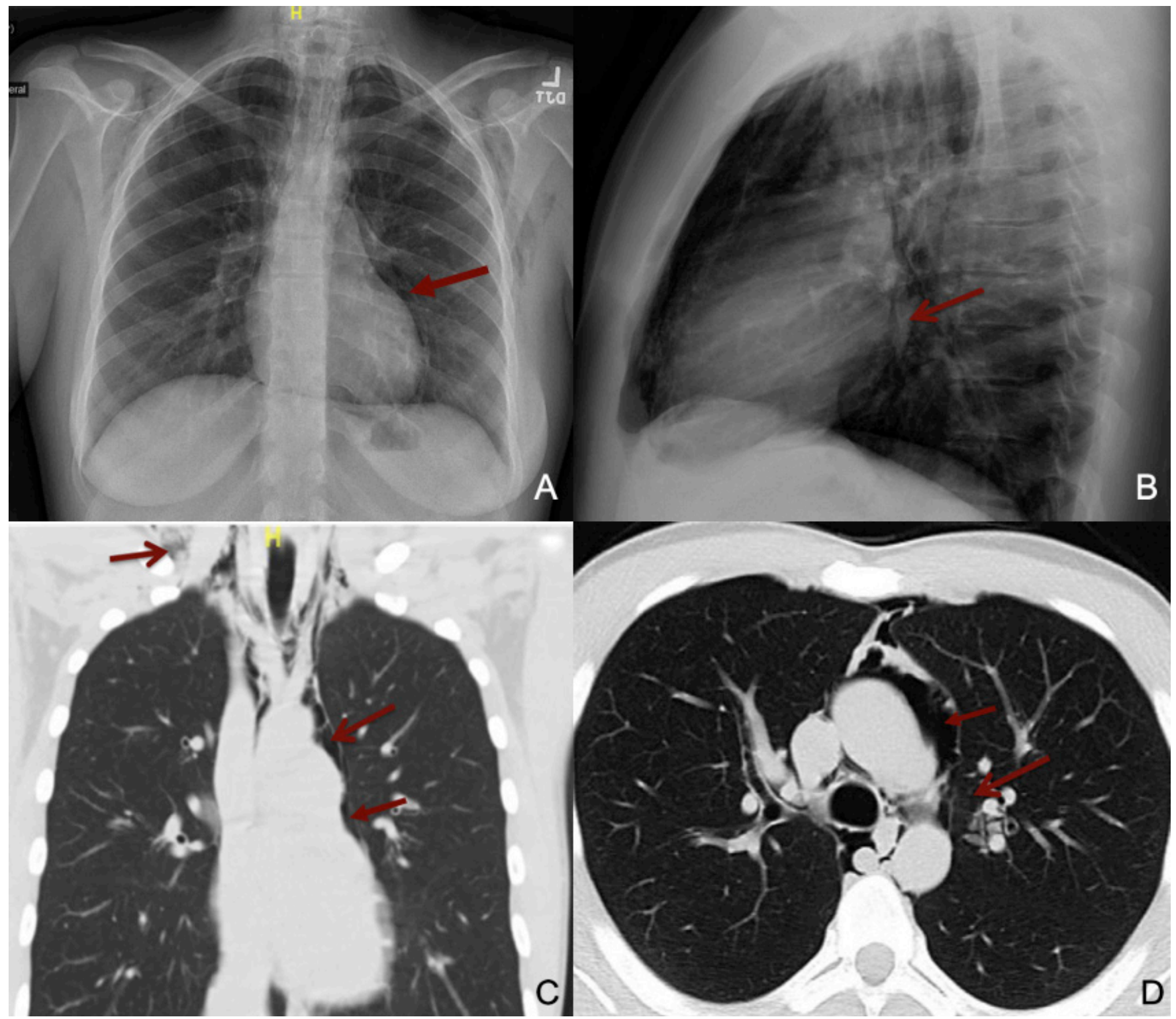

Figure 1 (A) Posterioranterior (PA) chest X-ray demonstrates pneumomediastinum in the anterior and middle mediastinum extending into the cervical soft tissues. (B) Lateral chest X-ray view: lucent striations seen in the mediastinum and air is visualised around the pulmonary vasculature. (C) Coronal CT chest with lung windows shows significant air present in middle mediastinum extending into the cervical soft tissues. (D) Axial CT of the chest with lung windows demonstrates air extending into the pericardial cavity.

fewer than 30 total patients. We aimed to evaluate the frequency of marijuana use in patients diagnosed with SPM and the extent to which physicians elicit a detailed smoking history. We further characterised the clinical presentation, presence of additional risk factors and management of these patients.

\section{METHODS}

This retrospective chart review was performed at Rhode Island Hospital, an urban 719-bed tertiary care centre, in Providence, Rhode Island, USA. We included patients diagnosed with radiograph-confirmed PM between 1 January 2016 and 31 December 2016. We excluded patients who had PM due to identifiable secondary causes of PM including trauma, lung malignancy, ventilator-associated lung injury, recent surgical procedure, recent intubation or other iatrogenic aetiologies as determined by chart review. The remaining cases were reviewed for reports of inhaled marijuana. These patient charts were reviewed in detail for demographics, clinical presentation and management. Mechanism, duration, frequency and temporal relationship with marijuana use to onset of symptoms were recorded if documented by providers. Patients who were documented to use daily or multiple times a week were classified as 'frequent use', and all other cases classified as 'infrequent use'. We recorded whether clinicians documented that they had given specific counselling to the patient on either the 
avoidance of inhalational marijuana or the relationship between smoking and their clinical symptoms.

\section{RESULTS}

We identified 147 patients with a coded diagnosis of $\mathrm{PM}$ /interstitial emphysema, of which 126 met exclusion criteria. Of the 21 remaining cases of PM, 14 had documentation of inhaled marijuana $(66.7 \%)$. Demographics, concurrent risk factors, clinical presentation and management are summarised in table 1 (patient-specific details in online supplementary file 1). All but one patient had one or more established risk factors for the development of SPM including smoking tobacco, illicit drug use, coughing or vomiting. Two patients had suspected cannabis hyperemesis syndrome. Half of patients reported daily or more frequent use. Three patients reported symptoms directly during or after smoking marijuana, while one described the onset of symptoms after exhaling against a closed glottis (though did not specify if during marijuana use). Temporality was not described in other cases. One patient reported the use of a 'large bong' while another reported using a 'face mask' but no further details were documented. Chest pain was the most common symptom (78.6\%). Tachycardia of $>100 \mathrm{bpm}$ was present in $57 \%$ of patients (range: 110-140). The majority of patients were admitted $(71.4 \%)$ with an average length of stay of 2.2 days (SD 1.5). All patients had a chest X-ray while additional imaging including chest CT and formal barium or gastrografin swallow evaluations were performed in $71.4 \%$ and $57.1 \%$ of patients, respectively. No patients underwent endoscopy or bronchoscopy. Counselling specifically related to marijuana use was documented in $50 \%$ of cases, the majority of which focused on cessation of marijuana. Two patients were counselled to avoiding strained breathing manoeuvres.

\section{DISCUSSION}

Over the course of 12 months, 14 of 21 cases $(66.7 \%)$ of SPM occurred in the setting of marijuana use, with half of patients reporting daily or more frequent use, suggesting that marijuana may be an underappreciated risk factor. All but one patient had at least one other established risk factor (eg, vomiting, coughing) suggesting that marijuana inhalation may have contributed, and was the most likely precipitating factor in at least three patients where a temporal relationship was documented. The co-occurrence of multiple risk factors suggests a possible multifactorial or additive effect.

The pathophysiology of marijuana-related SPM is likely due barotrauma during breathing manoeuvres, which can occur with the introduction of a relative pressure gradient between the alveoli and their vascular structures. An increase in alveolar pressure ultimately leads to increased alveolar pressure, rupture of the alveolar septa, collapse of the adjacent vascular structures and air dissection around the peribronchial and perivascular sheaths. This phenomenon is called the 'Macklin
Table 1 Summary of demographic data and clinical management in 14 patients with pneumomediastinum and marijuana use

\begin{tabular}{|lc}
\hline Demographics and risk factors & $\mathbf{n}(\%)^{\star}$ \\
\hline Age (years, SD) & $22.5(3.3)$ \\
\hline BMI (SD) & $25(4.2)$ \\
\hline Male & $9(64.3)$ \\
\hline Asthma exacerbation & $1(7.1)$ \\
\hline Vomiting & $8(57.1)$ \\
\hline Coughing & $6(42.9)$ \\
\hline URI symptoms & $4(28.6)$ \\
\hline Cocaine & $2(14.3)$ \\
\hline Opiates & $3(21.4)$ \\
\hline Tobacco & $2(14.3)$ \\
\hline One risk factor & $5(35.7)$ \\
\hline Two or more risk factors & $8(57.1)$ \\
\hline Frequency of marijuana use & \\
\hline Daily or more & $7(50.0)$ \\
\hline Less than daily & $3(21.4)$ \\
\hline Use not quantified & $4(28.6)$ \\
\hline Documented smoking apparatus & $2(14.3)$ \\
\hline Documented temporal onset & $3(21.4)$ \\
\hline Presenting signs/symptoms & \\
\hline Chest pain & $11(78.6)$ \\
\hline Dyspnoea & $8(57.1)$ \\
\hline Neck pain or odynophagia & $5(35.7)$ \\
\hline Palpable crepitus & $8(57.1)$ \\
\hline Clinical management & \\
\hline Inpatient admission & $10(71.4)$ \\
\hline Tachypnoea $>20$ breaths per minute & $1(7.1)$ \\
\hline Tachycardia $>100$ bpm & $8(57.1)$ \\
\hline Oxygen requirement & $2(14.3)$ \\
\hline Chest X-ray & $14(100.0)$ \\
\hline Chest CT & $10(71.4)$ \\
\hline Swallow evaluation & $8(57.1)$ \\
\hline Counselling & $4(28.6)$ \\
\hline LOS (days, SD) & $7(50.01)$ \\
\hline (y) & $2.2,1.5$ \\
\hline
\end{tabular}

${ }^{*} \mathrm{n}(\%)$ unless otherwise noted.

BMI, body mass index; LOS, length of stay; URI, upper respiratory infection.

effect $^{, 23}$ and can be achieved via inspiration against a closed airway (Muller's manoeuvre) after forced exhalation or exhalation against a closed glottis or airway (Valsalva manoeuvre). Both are common manoeuvres in marijuana users. ${ }^{15}$

In the case of the Valsalva manoeuvre, or forcible exhalation or breath holding against a closed glottis, a pressure gradient is created by raising intrathoracic pressure, 
leading to alveolar overdistension and rupture into the lower pressure perivascular space. ${ }^{15}$ Alternatively, with Muller's manoeuvre, attempted inspiration against a closed glottis or successive inhalation through a high-resistance smoking apparatus (such as a bong) results in a drop in intrathoracic and perialveolar pressure, an increase in alveolar air volume, a subsequent transmural pressure gradient, alveolar distension and rupture, and transmission of air from the pleura into the mediastinum. ${ }^{1524}$ Both manoeuvres result in shearing damage and air leakage along the vessels and bronchi into the mediastinal structures. ${ }^{1524}$

Positive pressure devices have been linked to barotrauma and PM, though SPM can occur even in the absence of a smoking device. ${ }^{10}$ There are no peer-reviewed studies on the effects of different methods of smoking cannabis on lung injury. ${ }^{25}$ In our study, physicians document the mechanism of smoking (via a 'large bong' and a 'face mask') in only two cases, and in one case a patient described exhaling against a closed glottis.

In addition to barotrauma, a direct toxic effect of the inhaled substance and heat may contribute to pulmonary damage and PM, though never proven pathologically. ${ }^{26}$ Marijuana may also contribute to the development of SPM by way of inducing cyclic vomiting. Two of the patients had suspected cannabinoid hyperemesis syndrome. However, in two other patients, vomiting occurred after the onset of the characteristic chest pain, suggesting SPM had already developed.

This study has a number of limitations. As a small retrospective case series, broader epidemiological conclusions cannot be drawn. Patients not disclosing marijuana use and providers failing to document social histories may result in under-reporting of this association. Neither the duration nor exact frequency of smoking was precisely quantified due to lack of reporting, though are of epidemiologic interests as future studies may seek to determine if a cumulative effect of smoking is present.

Our retrospective study identifies marijuana use as a possible risk factor in the development of SPM in 14 of $21(66.6 \%)$ patients. The frequent presence of multiple risk factors suggests a possible additive effect. The mechanism of injury may be caused by or potentiated by acute or chronic barotrauma from breathing manoeuvres used during smoking, chemical toxicity, or by inducing cyclic vomiting. Given current advances in the legalisation of recreational marijuana and the increasing use of medical marijuana, further investigation into the risks of specific smoking manoeuvres and delivery device used is necessary. It is prudent for physicians to obtain a detailed smoking history including the duration, frequency, mechanism of use and temporal relationship with smoking in patients presenting with SPM in order to provide appropriate counselling.

Contributors ZFW wrote the manuscript, performed data collection and analysis. SG assisted with data collection. AF supervised data collection and contributed to final manuscript. All authors discussed the results and contributed to the final manuscript.
Funding The authors have not declared a specific grant for this research from any funding agency in the public, commercial or not-for-profit sectors.

Competing interests None declared.

Patient consent for publication Not required.

Ethics approval This project was approved by the Rhode Island Hospital Institutional Review Board (IRB).

Provenance and peer review Not commissioned; externally peer reviewed.

Data sharing statement No additional data are available.

Open access This is an open access article distributed in accordance with the Creative Commons Attribution Non Commercial (CC BY-NC 4.0) license, which permits others to distribute, remix, adapt, build upon this work non-commercially, and license their derivative works on different terms, provided the original work is properly cited, appropriate credit is given, any changes made indicated, and the use is non-commercial. See: http://creativecommons.org/licenses/by-nc/4.0/.

\section{REFERENCES}

1. Takada K, Matsumoto S, Hiramatsu T, et al. Management of spontaneous pneumomediastinum based on clinical experience of 25 cases. Respir Med 2008;102:1329-34.

2. Kouritas VK, Papagiannopoulos K, Lazaridis G, et al. Pneumomediastinum. J Thorac Dis 2015;7(Suppl 1):S44-9.

3. Ebina M, Inoue A, Takaba A, et al. Management of spontaneous pneumomediastinum: are hospitalization and prophylactic antibiotics needed? Am J Emerg Med 2017;35:1150-3.

4. Johnson JN, Jones R, Wills BK. Spontaneous pneumomediastinum. West J Emerg Med 2008;9:217-8.

5. Tetrault JM, Crothers K, Moore BA, et al. Effects of marijuana smoking on pulmonary function and respiratory complications: a systematic review. Arch Intern Med 2007;167:221-8.

6. Mégarbane B, Chevillard L. The large spectrum of pulmonary complications following illicit drug use: features and mechanisms. Chem Biol Interact 2013;206:444-51.

7. Fiorello A, Vicidomini G, Santini M. Marijuana smokers and lung bullae. Eur J Cardiothorac Surg 2008;34:706-7.

8. Tashtoush B, Gonzalez-Ibarra F, Memarpour R, et al. Vanishing lung syndrome in a patient with HIV infection and heavy marijuana use. Case Rep Pulmonol 2014;2014:1-4.

9. de Moore GM, Baker J, Bui T. Psychogenic vomiting complicated by marijuana abuse and spontaneous pneumomediastinum. Aust $N Z J$ Psychiatry 1996;30:290-4.

10. Luque MA, Cavallaro DL, Torres M, et al. Pneumomediastinum, pneumothorax, and subcutaneous emphysema after alternate cocaine inhalation and marijuana smoking. Pediatr Emerg Care 1987;3:107-9.

11. Miller WE, Spiekerman RE, Hepper NG. Pneumomediastinum resulting from performing Valsalva maneuvers during marihuana smoking. Chest 1972;62:233-4.

12. Birrer RB, Calderon J, Pneumothorax CJ. Pneumothorax, pneumomediastinum, and pneumopericardium following Valsalva's maneuver during marijuana smoking. $N$ Y State $J$ Med 1984;84:619-20.

13. Heppner HJ, Sieber C, Schmitt K. "Usual" cannabis abuse producing an unusual incident. Dtsch Med Wochenschr 2007;132:560-2.

14. Fajardo LL. Association of spontaneous pneumomediastinum with substance abuse. West $J$ Med 1990;152:301-4.

15. Hazouard E, Koninck JC, Attucci S, et al. Pneumorachis and pneumomediastinum caused by repeated Müller's maneuvers: complications of marijuana smoking. Ann Emerg Med 2001;38:694-7.

16. Koral E, Brasseur P. Spontaneous pneumomediastinum and marijuana. J Radiol 2007;88:390-2.

17. Herrejón Silvestre A, Blanquer Olivas J, Simo Mompo M, et al. Pneumothorax due to drug inhalation. An Med Interna 1992;9:137-9.

18. Dajer-Fadel WL, Argüero-Sánchez R, Ibarra-Pérez C, et al. Systematic review of spontaneous pneumomediastinum: a survey of 22 years' data. Asian Cardiovasc Thorac Ann 2014;22:997-1002.

19. Banki F, Estrera AL, Harrison RG, et al. Pneumomediastinum: etiology and a guide to diagnosis and treatment. Am J Surg 2013;206:1001-6.

20. Perna V, Vilà E, Guelbenzu JJ, et al. Pneumomediastinum: is this really a benign entity? when it can be considered as spontaneous? our experience in 47 adult patients. Eur $J$ Cardiothorac Surg 2010;37:573-5. 
21. Mattox KL. Pneumomediastinum in heroin and marijuana users. JACEP 1976;5:26-8.

22. Iyer VN, Joshi AY, Ryu JH. Spontaneous pneumomediastinum: analysis of 62 consecutive adult patients. Mayo Clin Proc 2009;84:417-21.

23. Macklin CC. Transport of air along sheaths of pulmonic blood vessels from alveoli to mediastinum. Arch Intern Med 1939;64:913.

24. Al-Mufarrej F, Badar J, Gharagozloo F, et al. Spontaneous pneumomediastinum: diagnostic and therapeutic interventions. $J$ Cardiothorac Surg 2008;3.
25. Ribeiro LIG, Ind PW. Effect of cannabis smoking on lung function and respiratory symptoms: a structured literature review. NPJ Prim Care Respir Med 2016;26:16071.

26. Panacek EA, Singer AJ, Sherman BW, et al. Spontaneous pneumomediastinum: clinical and natural history. Ann Emerg Med 1992:21:1222-7.

27. Koullias GJ, Korkolis DP, Wang XJ, et al. Current assessment and management of spontaneous pneumomediastinum: experience in 24 adult patients. Eur J Cardiothorac Surg 2004;25:852-5. 